\title{
Urban management foundation in risk reduction
}

\author{
C. O. Gociman ${ }^{1}$, T. C. Florescu ${ }^{1}$, E. S. Georgescu ${ }^{2}$, \\ C. I. Moscu ${ }^{1} \&$ I. M. Stanescu ${ }^{1}$ \\ 1 "Ion Mincu, " University of Architecture and Urban Planning, Romania \\ ${ }^{2}$ The National Institute for Research and Development, \\ URBAN-INCERC, Romania
}

\begin{abstract}
The methodology of managing the security habitat exposed to multi-hazard is based on a matrix determined relation between the reference value and the area condition value. The reference value $=\sum$ cultural, functional, affiliation value $(0-5)$.

Many studies are supporting the idea of the mental city, kept in the memory of every individual. The spatial footprint belongs to the personality of everyone and its de-structuring creates instability and stress.

Thus, the value of spatial perception becomes important in relation to the space and surely it is different from one individual to another, depending on age, gender, education, religion, ethnics.

The condition value or vulnerability value refers to the degree of the urban system, as the sum of its components - built space (buildings, installations) and free space (streets, alleys, green spaces, water) can be affected by one multihazard during a time interval. The analysis of this value is extremely complex and it is based on the application of the specific quality norms.

The status value $\sum$ safety value (structural, exploitation, protection from fire), environment value (hygiene, thermal protection, sound protection, waterproofing, lighting) (0-5).

The analysis on every criterion is based in mapping the entire built space according to the specialty methodologies. According to statistic studies carried out by the Romanian Academy after the earthquake from 1977, the affiliation to a building group defined as structural behaviour, depending on the number of
\end{abstract}


levels, material and construction period was identified. Mapping with values between 0 and 5 was extended also to the other criteria.

The structural vulnerability condition evidently determines the vulnerability of the population, as scenarios show.

The intervention methods are mapped in 3 groups - maintenance, amelioration and transformation, each with specific sub-groups and they regard the rehabilitation of the habitat, but this fact does not cover the entire problematic of the urban tissue.

Urban reorganization will be founded by complex risk analyses, which, through specific risk scenarios will estimate the losses and identify the opportunity of creating a security area centered on a security hub.

The security ensemble is the urban area composed of a habitat which can be functional to intervention and which has in its center the security hub for emergency locations able to locally manage the sanitary-logistic and accommodation crisis.

The area has to have a supporting infrastructure network - transportation ways correctly dimensioned, which to allow the evacuation of the population, preferably underground parking lots which can function as emergency shelters, utilities with flexible connections and alternative independent sources built based on a correct pre-disaster management. This will allow the control over the central intervention areas, transportation system, emergency sanitary system and civil protection.

Keywords: habitat, transport, public space, security hub, risk reduction, urban strategies.

\section{Introduction}

Currently, the urban population represents more than $50 \%$ of the global population. The cost of restoration and reconstruction of the urban tissue and of the built area, affected by multi-hazard reported by the Work Bank during the last 3 decades, are over 4 trillion $\$$ and re-approach all methods for reducing the risk. The DRR (disaster risk reduction) is more and more focused on prevention and answer of the territory, mainly of the urban space to multihazard.

Urban design has to be a holistic one, to ensure sustainability and resilience of the system.

UNISDR recognizes that the urban design and management are main factors in the management of risk reduction.

Applying the issue of sustainable urban development theory launched by the Brundtland report in 1987 "Our common future" by the World Commission on Environment and Development of the United Nations) has developed, in time, a series of approaches.

The issue analyzed in the Brundtland Report is extremely diverse and complex, from various fields and at various levels, covering a very wide range, which cannot be presented in extenso, nor must it be excessively schematized. What should be mainly emphasized is the conclusion formulated, namely the 
need for "another type of development", capable to ensure, on a long term, the economic increase, improvement of the environment and preservation of natural resources.

This type of development, defined as "Sustainable development is the development that meets the needs of the present generation without compromising the ability of the future generation to meet their own needs".

Sustainable development therefore has to meet a number of three synthesis conditions, namely: to maintain the quality of life in general; to ensure a permanent access to natural resources; to avoid any environmental destructions with final character.

This definition posits the relation between 3 notions - development, need and future generation. Sustainability introduces the need to apply ten principles.

The principle of precaution - in making some decisions; the principle of management of request - selecting the optimum requests to negotiate in divergence; the solidarity principle looking for compliance with the general interest; the principle of environmental efficiency means tracking a maximum benefit in every natural resources unit used and waste produced by human activities; the principle of social-economic efficiency meaning reaching a maximum human benefit from each unit of economic activity; the principle of honesty which means solving a problem by the simplest and most economic adequate means; the principle of global thinking - local action understood on two coordinates, a horizontal one, territorial and a vertical one, of all the problems and fields of the human life where it develops, in close connection; the principle of fairness looking for sharing responsibility related to the quality of the life environment, internationally, between countries, up to the individual level; the principle of ecosystem approach within the sustainable development, on one side, an understanding of the natural environment which we have to respect based on understating its component ecosystems, and on the other side, understating other ecosystems that are not natural, included in the natural environment by assimilating them as ecosystems. This approach is frequently used by the specialists approaching the sustainable development issue, for phenomena that develop on various territorial levels, mainly for cities and the urban environment.

Agenda 21 - document of the Earth Summit in Rio de Janeiro (1992) proposes a program of implementation of the sustainable development to consider the need to live fairly in report with nature and "treats the sustainable human settlements".

\section{Urban sustainability}

The sustainable city is a dynamic balance between its components, support space (biotope) in relation to population antropogenosis (living) and economical and social environmental relations.

Sustainability indicators regard the optimization of three areas, ecology, economy and social-cultural, also refer to application of the sustainable development principles: ecological - protecting the resources and ecosystems; 
economical - economic performance, reducing the costs; social-cultural - on health, functionality of the cultural values and the users' satisfaction.

The optimum model of sustainable city has to consider determinations of the current situation, on criteria imposed and indexes obtained, of the city as exposed element, reporting value $=\sum$ cultural value, functionality and affiliation, as well as on those of status.

\subsection{Exposed elements of the urban tissue}

- Urban structure - compact, linear, poly-nuclear, diffuse, composed

- identifies, for the relation between sustainability and structure of the city "city form", an oscillation between extremes, from the high density compact model to that of a low density garden city.

The compact city is, according to Jenks et al. [7] a sustainable city as it encourages interaction, ensures services that reduce transportation and stimulates pedestrian movement.

- Public spaces - market and streets system historically built, determined by the circulation ring, radial, linear, irregular forms.

- Elements of anthropogenic natural environment - landforms, green spaces and water mirrors.

- Spaces built - developed in regular urban islands or in added disordered increase.

\subsection{Analysis of the exposed elements}

Attributes that identify sustainability are those derived from the principle of sustainable development, efficiency, responsibility, integrity, fairness, viability, accessibility and refer to the reporting value and status value.

\subsubsection{Reporting value $-\sum$ cultural, functionality and affiliation value} This will follow the next attribute:

- Liveliness - relation between the environment and the society

- Fairness - access to resources, services involving participation.

- Williams et al. [9] consider that a sustainable city is "user friendly" for its occupants, and promotes social equity.

As did Lynch in "The Image of the City" [10], Reijndorp and Hajer [11] in "In search of new public domain" identify a relation between the space built and the human perception determined by the patrimonial correspondence.

Wolpert [1] declares that the spatial foot print belongs to the personality of everyone and its destructuring creates instability and stress.

Gehl says in his book "Life between buildings: using public space" [12] that the development of the urban space depends on containing activities.

The appearance of residual spaces "junk space" is a possibility because of the urban dysfunctions which may save through clever intervention (Koolhas [13]).

Criteria of evaluation of certain spaces consider both the affective perception and the selective one related to their geometrical, dimensional, orientation, illumination and connectivity qualities. 


\subsubsection{Status value of exposed elements}

It's $\sum$ safety value (structural, exploitation, protection from fire), environment value (hygiene, thermal protection, sound protection, waterproofing, lightning) $0-5$.

The status value identifies the efficiency, responsibility and life quality of the urban structure.

- Economical and ecological efficiency identifies the decrease of global energy consumption of the city (buildings, transport, utilities).

- Responsibility is related to the preoccupation for reducing the resources consumption, prevention of pollution.

- Life quality (light and natural ventilation/hygiene/health).

Analysis of the value of status and vulnerability is determined mostly by the consumption of energy necessary for construction and transport within the two investment and maintenance states.

Of course, the investment does not necessarily refer to new construction but also to restoration, consolidation, rehabilitation of current built area affected by degradation and multi-hazard. Intervention decisions are the result of an interpolation between the analysis of the reporting value (cultural, functions and of perception) and that of the status value of use and vulnerability. These decisions involved maintenance, improvement, restoration (consolidation, restructuring) and reconstruction.

During the correct management of the urban tissue we have stages, such as design, construction and maintenance and demolishing, which each must benefit from the application of sustainability regarding the management of resources (energy, materials, workmanship).

\subsection{Exposed element: circulation system}

The system and dimensions of the transport routes are generated by the urban structure and the integrated centralized or non-centralized functional distribution. The compact city as a functional conglomerate offers near services and jobs reducing the need for transportation. The poly-nuclear system develops services around the multifunctional poles, offering quick connections with public transport, between poles (metro, urban trains, quick trams and non-polluting buses).

Diminishing the need for transportation and changing the transportation type has to be conducted in two directions, by encouraging the pedestrian movement with bikes and public transport (buses, trains).

\subsection{Transport: current and emergency accessibility}

The transport system is part of the ensemble of public spaces, markets and streets and represents the accessibility system of the population, of emergency goods, that may be the voluntary dispersion or the directed evacuation to shelter areas of the affected persons. 


\subsection{Exposed element: the population}

The density of population as result of some high urban indexes - percentage of occupation of the land $>50 \%$ A building / A land $>50 \%$ and coefficient of use of land $>3$ Ac developed / A land $>3$ is a natural consequence of the built areas. It may vary generally in relation to green spaces related to public infrastructure (roads, markets and green spaces and water mirrors) or considering the destructured areas with or without resources.

\subsection{Urban resilience}

The resilient city is characterized by special, functional diversity by social adaptability and scalar modularity.

Other definitions use redundancy as a reactive alternative, reactive flexibility as turn over learning and reorganization. All these characteristics belong to the ecosystem definition extended to the urban environment.

In the study "Resilience and stability of ecological systems", Holling [16] shows that resilience may apply to an ecological system only as adaptability, which supposes reorganization. Resilience was introduced in the management of risk reduction in 2005 together with Hyoyo Framework for Action HFA. In this context, resilience represents the capacity of a system exposed to multi-hazard to resist and to adapt.

Alan March defines urban resilience "as a connection between the spatialization of risk management and improvement of a risk profiles over time as a mechanism for integrality various activities and social, economic and built form outcomes.

\subsection{Urban management in DRR}

Mapping and multi-criteria assessment of the built space offers us the support for intervention operations on every object separately. Surely the adding of these operations can give us the scale of global interventions. If these interventions would take place, they would result in the creation of a rehabilitated and secure built space. The cost, duration and implementation modality of the interventions are answers which can be given in time. Mobilization of multi-disciplinary teams for the reference value assessment composed of cultural, functional and perception value in opposition to the assessment of the vulnerability status, environment quality is defined and limited from the point of view of resource availability.

The legislation and the constitutional aspects have to be considered also in relation to property and life protection. The situation is known, when out of lack of monetary funds for consolidation, some owners opposed the project and this has compromised the entire action, and this is a death sentence.

For consolidation, restoration, rehabilitation of a building, the financial support has to be developed within public-private associations with correctly assessed participation of the parties related to the value of the land, of the house and the investment. 
Of course, the problems are not only linked to the architectural and structural interventions, which are long term, but also the urban system has to be approached with priority and it includes the habitat and the public spaces, streets, squares, parks, gardens and critical infrastructure.

In the case of a hazard, the population is evacuated mainly to the exterior of the permanent habitat, since the open space is offering not only protection but also orientation, communication opportunities. The hazard forces the community to prompt help, triggering solidarity and leading to the emergence of voluntary leaders. But regardless of the hazard particularity, the community has to have a general action plan, with a known structure. Of course there must be local coordinators for the evacuation and leading to the shelters.

In an area affected by an earthquake as primary hazard, a space must be determined with a high level of safety, which cannot be affected by the possible collapse of other buildings and which can overtake the sheltering, residence, logistical assistance, health care, counseling, information and communication function.

The existence of victims, in which case the search and rescue operations have to be launched, the problems related to accessibility, the fluency of transportation are critical.

\section{Accessibility versus evacuation: sheltering}

Accessibility means streets unobstructed by debris, explosions of utilities, and the crowd of those chaotically going about their business, which leads to irremediable road congestions. Avoiding these situations of traffic management means measures of blocking the movement, by solving assistance problems on a local level.

If the inhabitants know and identify the emergency assistance spaces and associated services, they will not initiate trips easily and they will concentrate on other logistic services.

In other words, decentralizing assistance during crisis by activation of a polynuclear system of local protection locations will ease the permanent intervention activity.

The necessity of shelter-protection situations should be combined with evacuation.

Emergency sheltering on the spot is determined by: hazard unclear as continuity and triggering; moving is more dangerous than staying; there is no time to take action until hazard triggering.

\subsection{Short term sheltering in the space}

Pre-identified - schools, community hallways with the previous agreement from the space owners. These spaces have to be able to be converted and also to be energy independent.

Mass evacuation and sheltering for events with a significantly close area these need a special approach. 


\subsection{Return and recovery}

The decision to return depends on the area security - especially on observance of law and order; the return means a similar logistic to the evacuation, ensuring minimum services for the population - drinking water, minimal amenities, food.

But firstly, the people can take shelter in their own cars, to be as close as possible to the affected residential location. They will try to remain near their

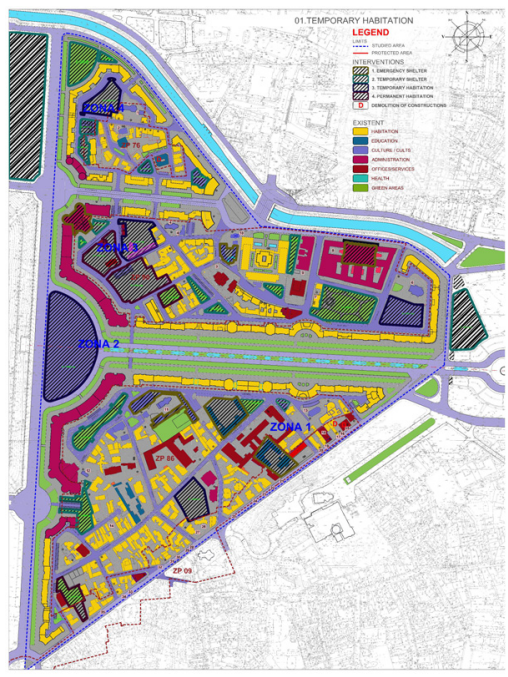

(a)

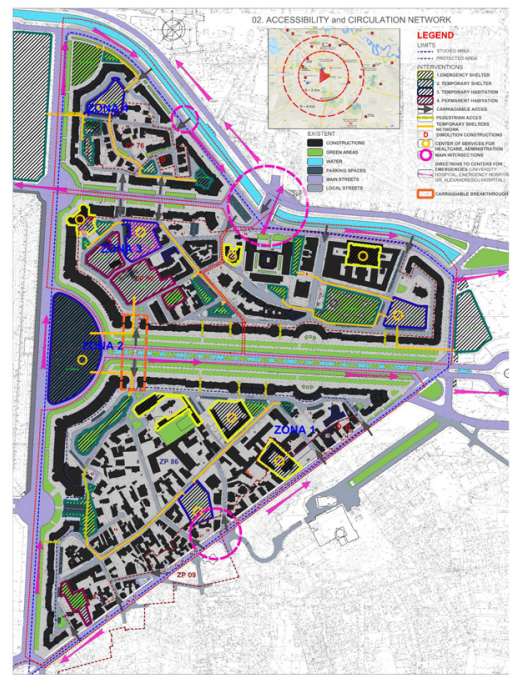

(b)

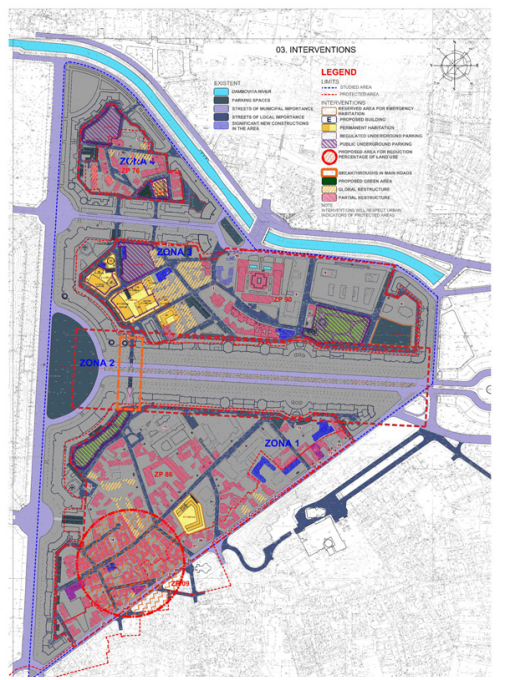

(c)

Figure 1: Urban risk management case study: central protected area in Bucharest (a) temporary habitation; (b) accessibility; (c) interventions. 
homes, near their properties and so they will not be far away from them. To this purpose, designing an individual protection system or a system for small group protection can increase the decentralization of the system. If the residence can be transform into a sleeping bag or a sleeping box, the other needs - food, sanitary needs, clothing - will be harder to solve, but they will be possible in a secondary stage with the help of the competent authorities.

In all urban assessments, the cars have created serious problems for the management of the evacuation. Thus, the construction of underground or overground parking lots to free the ground and make it available for access and pedestrians without intervention is a necessity for the daily life but at the same time it is solving the accessibility issue in case of emergency.

In the case of a safe space, every car can generate a safe container; in it, on it, near it - the protection space can be configured as a module in a system.

Triggering public or public-private investments for parking lots can be seen in conjunction with playgrounds, public gardens. The development of uneven green spaces over semi-buried parking lots can create a necessary symbiosis.

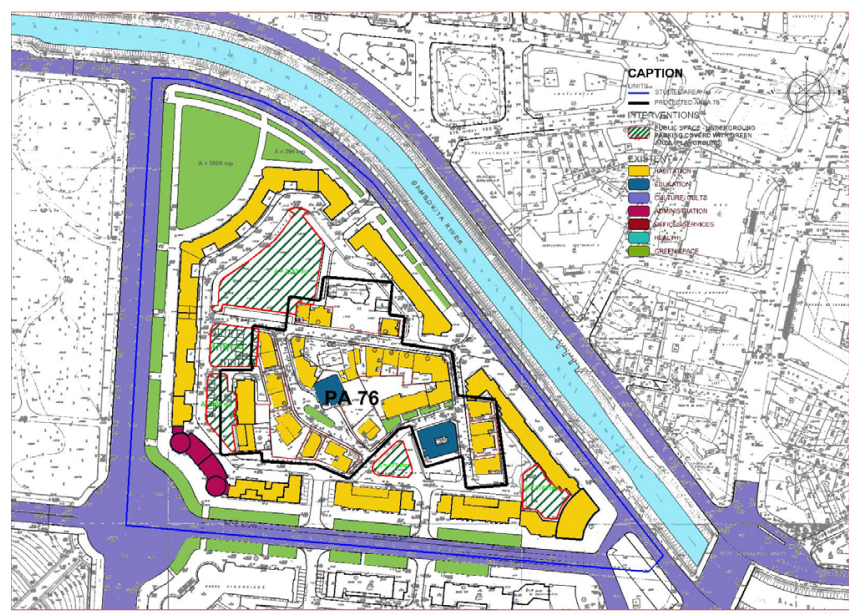

Figure 2: Proposals for shelter - parking (semiburied) with cover of a green area, playground.

In Bucharest, as in other cities in Romania, the pressure of the private car transportation has risen in the last decades, especially after the revolution. From a motorization index of 1 car to 10 inhabitants there is now one car to one inhabitant. Presently in Bucharest there are 1.5 million cars out of which there are $80 \%$ in the central area.

This fact is due to the lack of public policies of sustainable urban transportation development - pedestrian, bicycle transportation - or of public transportation (trains, metro, tram and bus system).

The start of developing public amenities - parking lots with community spaces and playgrounds together with developing alternative independent resources with flexible connections, can create public rescuing infrastructure. 


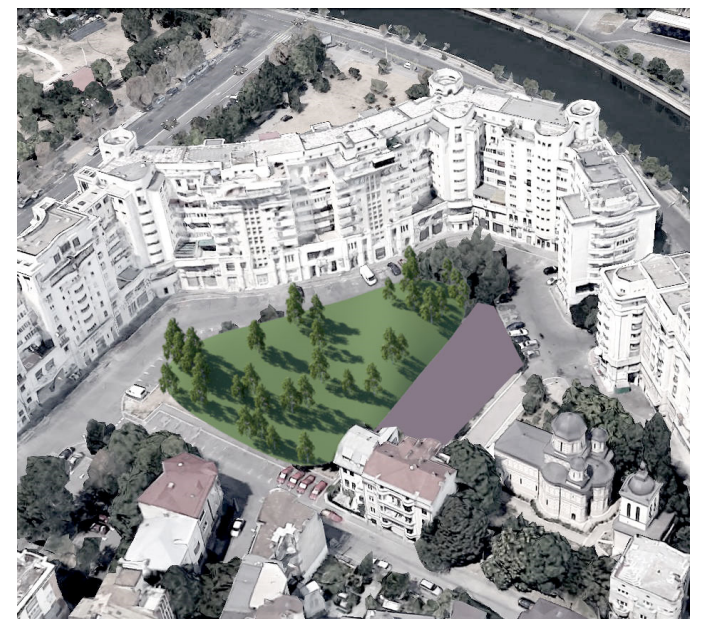

(a)

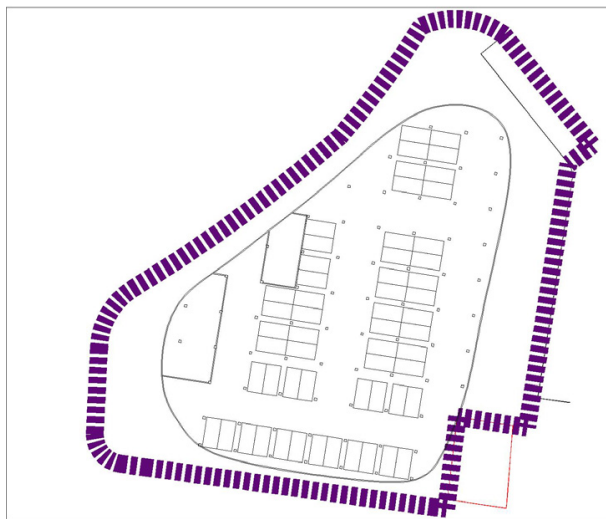

(b)

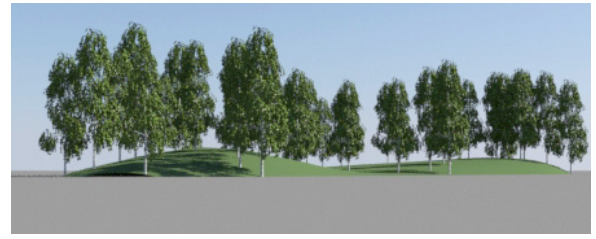

(c)

Figure 3: Semiburied parking with cover of a public green area and playground (Mihai Voda Square, Bucharest).

The theory of the philosopher Feyerabend [18] regarding the "Conquest of Abundance" according to which cooperation is necessary and there are no differences between the producers and the consumers - hence the emergence of the prosumer (responsible citizens).

The attention shifted from sustainability to resilience, which implies a shift from dislocation certain values to their balancing in adaptability. 
The interdependence producer-consumer is obvious, but the emergence of the prosumer, responsible citizen, in reference to the support space can modify the equation.

This fact is developing a co-creative space based on collective creation of smart-users.

\section{Conclusion: urban strategies}

Risk reduction through city planning strategies must be substantiated, much like the architecture strategy, through the same methodology:

- Identifying multi-hazard and preparation of hazard maps.

- Identifying elements exposed to multi-hazards: urban space - square, street, pedestrian space, public garden/population/public, civic activities; gatherings; shows; tourism, sport events; trade - fairs, exhibitions/urban infrastructure - transportation, utilities.

- Reference value analysis, cultural value, functional value, perception value.

- Status value analysis (vulnerability analysis), security value, environment value.

- Risk analysis through own specific risk scenarios cumulated to the analysis of the neighboring built space.

- The intervention decisions are linked to the understanding of the architecture strategies' conclusions and the structure pertaining to the built space as well as to the conclusions specific for the urban space
i. $\quad \mathrm{A} / \mathrm{B}$ - maintenance/conservation;
ii. $\quad \mathrm{C} / \mathrm{D} / \mathrm{E} / \mathrm{F}-$ restoration/reconstruction;
iii. $\mathrm{G} / \mathrm{H}-$ demolition/new space.

Urban reorganization will be founded by complex risk analyses, which, through specific risk scenarios will estimate the losses and identify the opportunity of creating a security area centered on a security hub.

The area has to have a supporting infrastructure network - transportation ways correctly dimensioned, which to allow the evacuation of the population, preferably underground parking lots which can function as emergency shelters, utilities with flexible connections and alternative independent sources built based on a correct pre-disaster management. This will allow the control over the central intervention areas, transportation system, emergency sanitary system and civil protection.

The security ensemble is the urban area composed of a habitat which can be functional to intervention and which has in its center the security hub for emergency locations able to locally manage the sanitary-logistic and accommodation crisis.

\section{Acknowledgement}

Funding for this research was provided by the Romanian Ministry of Education and Scientific Research, UEFISCDI Agency, in the framework of the National Plan for Research, Development and Innovation, PN II, Partnership Program, 
Project "Urban Blocks in Central Protected Area in Multiple Hazard Approach Assessment, Mapping and Strategies for Risk Mitigation. Case Study: Bucharest Destructured Zone by Razing Occuring in the Communist Period" under Contract no. 53/2012, project URBASRISK.

\section{References}

[1] Wolpert, J., Migration as an adjustment to environmental J of Social Issues, 1966

[2] UNISDR, “UNISDR Terminology on Disaster Risk Reduction” 2009

[3] World Commission on Environment and Development (WCED): Our Common Future, Brundtland Report, Oxford University Press: London 1987

[4] Agenda 21 - Earth Summit, Rio de Janeiro 1992

[5] Guideline for Sustainable Building Federal Ministry for the Environment Nature Conservation Building and Nuclear Safety, 2012, Berlin, Germany

[6] Monghtin C, Urban Design: Green Dimensions, Architectural Press, London 1996

[7] Jenks, M. Burton, E. \& Williams, K. (eds). The Compact City: A Sustainable Urban Form? E and F N Spon; London 1996

[8] Gociman C, Moscu C., Georgescu E.S., The relationship between identity and vulnerability values in carrying out interventions in protected urban areas, Wit Transactions on Ecology and The Environment, vol.193, 2015, WIT Press

[9] Williams K, et al., Achieving Sustainable Urban Form, E and F N Spon: London, 2000

[10] Lynch, K. - The Image of the City, Cambridge, Mass. Technology Press and Harvard Univ. Press, 1960

[11] Reijndorp Arnold, Maarten Hajer; In search of new public domain. Analysis and strategy, NAI publishers, Rotterdam, 2001

[12] Gehl Jan, Life between buildings: using public space; Danish Architectural Press, Copenhagen 1971

[13] Koolhas Rem, JunkSpace, October, 100.2002

[14] Hillman, M. In favour of the Compact City, in Jenks, M., Burton, E.\& Williams, K (eds). The Compact City: A Sustainable Urban Form? E and F N Spon: London, 1996

[15] Evacuation and shelter guidance, H.H. Government, 2013, Cabinet Office 79, Whitehall

[16] C.S. Holling, Resilience and Stability of Ecological Systems, Annu Rev. Ecol. Syst., vol. 4, 1973

[17] United Nations, International Strategy for Disaster Reduction Hyogo Framework for Action 2005-2015: Building the Resilience of Nations, 2005

[18] Feyerabend, P., Conquest of Abundance, a tale of abstraction versus the richness of being, ed. B. Terpstra, The University of Chicago Press, Chicago and London 